\title{
PRINCÍPIOS GERAIS DE DIREITO CONTRATUAL APLICÁVEIS À DÍVIDA EXTERNA DOS PAÍSES EM DESENVOLVIMENTO*
}

\author{
Álvaro Villaça Azevedo \\ Diretor da Faculdade de Direito da Universidade de São Paulo \\ ex-Diretor da Faculdade de Direito da Universidade Mackenzie-SP
}

Resumo:

Os princípios gerais de Direito apresentam-se com força normativa nos sistemas jurídicos contemporâneos, porque encontram seu fundamento, sua força, principalmente, no Direito Natural.

Por essa razão, esses princípios devem ser observados nas contratações, seja no âmbito nacional, seja no internacional, sob pena de desequilibrarem-se as relações jurídicas.

Assim, salientam-se o princípio da boa-fé, também objetivamente considerada, o da liberdade contratual, para maior justiça nas negociações, e o da função social do contrato, como meio justo de entendimento entre os homens.

Também, destaca-se o princípio da comutatividade dos contratos e da eqüidade, para que as partes sejam iguais, no tocante às prestações devidas. Daí, o princípio da cláusula rebus sic stantibus, que, considerada imanente em todos os contratos, autoriza sua resolução; portanto, independentemente de culpa, desde que se desequilibrem as posições das partes, em razão de fato imprevisto, imprevisível e extraordinário, com prejuízo maior de um dos contratantes, dá-se a resolução. $\mathrm{O}$ contrato, desse modo, torna-se muito oneroso a uma das partes.

Todavia, em regime inflacionário, a inflação não é imprevisível, o que dificulta a aplicação dessa teoria da imprevisão.

Daí, o resumo de nossa proposta:

a. Aplicação, pura e simplesmente, da teoria da onerosidade excessiva, causadora de lesão, independentemente da teoria da imprevisão ou da cláusula rebuc sic stantibus. O simples desequilíbrio contratual, objetivamente considerado, causa a necessidade de revisão contratual, com a conseqüente reposição ao statu quo.

b. Impossibilidade de alteração unilateral, pelos credores, das taxas de juros, sob pena de atuação abusiva e mesmo ilícita, causando a nulidade dessa modificação realizada sem o mútuo consenso dos contratantes.

\footnotetext{
* Pronunciamento, revisto, feito na sede do Parlamento Latinoamericano, em São Paulo-SP, Brasil, por ocasiāo da Mesa Redonda de Direito dos Povos Latinoamericanos Dívida Externa, em 27.04.95, e no "II Seminario Giuridico Internazionale" sobre "Debito Internazionale - Principi Generali del Diritto - Corte Internazionale di Giustizia", de 25 a 27 de maio de 1995, em Roma.
} 
c. Necessidade de respeitar-se, quanto aos débitos dos contratos existentes, o parecer da Corte Internacional de Justiça de Haia, a que deve ser submetida a questão sobre a dívida externa dos Países em desenvolvinento, ou, se for o caso, o parecer da Organização Internacional do Trabalho (OIT).

d. No tocante aos contratos futuros, necessidade de inserir, neles, cláusulas de arbitragem, escolhendo, de preferência, o árbitro e seus eventuais substitutos, em ordem cronológica, na cláusula contratual. Esse árbitro deve ser, de preferência, a Corte Internacional ou outro Órgão equivalerite.

e. Incentivo aos Países em desenvolvimento à implantação de projetos de conversão da dívida externa de natureza ecológica.

Deve, assim, existir uma compreensão geral dos credores dos Países em desenvolvimento para que a humanidade cresça e se espiritualize, na idéia da construção de um mundo novo, fraternal e amigo, em que a matéria seja secundária nos projetos de aprimoramento da cultura dos povos, da justiça social e do bem-comum.

Abstract:

The general principles of Law come with normative force in the contemporary juridical systems, because they find its foundation, its force, mainly, in the Natural Right.

For that reason, those principles should be observed in the recruitings, be in the national ambit, be in the international, under feather of unbalancing the juridical relationships.

Thus, they are pointed out the beginning of the good-faith, also objectively considered, the one of the contractual freedom, for larger justice in the negotiations, and the one of the social function of the contract, as a fair means of understanding among the men.

Also, stands out the beginning of the commutativity of the contracts and of the justness, so that the parts are the same, concerning the due installments. Thence, the beginning of the clause rebus sic stantibus, that, considered immanent in all the contracts, it authorizes its resolution; therefore, independently of blame, since both parts' positions lose their balance, due an unexpected fact, unexpected and extraordinary, with larger damage of one of the contracting parties, the resolution is applied. The contract, in that way, becomes very onerous to one of the parts.

Though, in inflationary regime, the inflation is not unexpected, what hinders the application of that theory of the improvidence.

Thence, the summary of our proposal:

a. Application, pure and simply, of the theory of the excessive onerousness, lesion foister, independently of the theory of the improvidence or of the clause rebus sic stantibus. The simple contractual unbalance, objectively considered, it causes the need of contractual revision, with the consequent replacement to the statu quo.

b. Impossibility of unilateral aiteration, by the creditors, of the interest rates, under feather of abusive and even illicit performance, causing the nullity of this modification accomplished without the mutual consent of the contracting parties. 
c. Need to respect, for the debits of the existent contracts, the opinion of the International Court of Justice of The Hague, to whom should be submitted the subject on the foreign debt of the Countries in development, or, in case of need, the opinion of the International Organization of Work (IOW).

d. Concerning the future contracts, need to insert, in them, arbitration clauses, choosing, preferably, the referee and its eventual substitutes, in chronological order, in the contractual clause. That referee should be, preferably, the International Court or other equivalent Organ.

e. Encouragement to the Countries in development due the implantation of projects of conversion of the foreign debt with ecological nature.

There must be, thus, a general understanding of the creditors of the Countries in development so that the humanity grows and espiritualizes, in the idea of the construction of a new, fraternal and friendly world, in that the matter is secondary in the projects of refinement of the culture of the people, of social justice and of welfare.

Unitermos: princípios gerais de Direito; modificação unilateral da taxa de juros; efeitos da onerosidade excessiva

\section{Sumário:}

A - Princípios Gerais de Direito.

1 Generalidades.

2 Princípio da boa-fé.

3 Princípio da liberdade contratual.

4 - Princípio da função social do contrato.

5 Princípio da comutatividade dos contratos e da eqüidade.

6. Princípio da cláusula "rebus sic stantibus"

7 Princípio da onerosidade excessiva e lesão objetiva.

B - Modificação unilateral da taxa de juros.

C Efeitos da onerosidade excessiva.

D Conversão da dívida externa em projetos de natureza ambiental.

E Resumo de nossa proposta. 
A Princípios Gerais de Direito.

1 Generalidades.

1. Os princípios gerais de direito apresentam-se com força normativa nos sistemas jurídicos contemporâneos, principalmente porque encontram sua força no próprio Direito Natural.

2. Já Marco Tullio Cícero (De off., 1, 101) dizia que a razão ensina e explica o que deve ser feito e o que deve ser evitado ("ratio docet et explanat quid faciendum fungiendumve sit").

3. Por isso, esses princípios não podem ser olvidados, nas contratações, quer no âmbito nacional, quer no internacional, sob pena de desequilibrarem-se as relações jurídicas, com o enriquecimento de um em detrimento do empobrecimento do outro contratante.

4. Daí, porque alguns princípios devem ser lembrados nas contratações dos povos, para que se irmanem, na ajuda um do outro, sem os excessos.

2 Princípio da boa-fé.

5. O princípio da boa-fé deve ser, antes de tudo, mencionado, pois ele assegura o acolhimento do que é lícito e a repulsa ao ilícito.

6. A contratação de boa-fé é a essência do próprio entendimento entre os homens e a presença da ética nos contratos.

Sim, porque a aplicação do princípio da boa-fé traz para a ordem jurídica um elemento de Direito Natural, que passa a integrar a norma de direito.

7. Todos os Códigos e todos os sistemas jurídicos são escudados no princípio da boa-fé, que supera, até, o princípio da nulidade dos atos jurídicos, pois os atos nulos, em certos casos, produzem efeitos, e até os atos inexistentes, para premiar a atuação de boa-fé, como é o caso da validade do pagamento ao credor putativo, da transmissão da herança ao herdeiro aparente, dos efeitos em favor do cônjuge de boa-fé no casamento putativo. Nesses casos, não vigora o princípio, segundo o qual o que é nulo não produz efeito ("quod nullum est nullum effectum producit"). 
Destaque-se, neste ponto, primeiramente, o art. 1.337, do Código Civil italiano, de 1942, pelo qual os contratantes, "no desenvolvimento das tratativas e na formação do contrato, devem comportar-se segundo a boa-fé"

A seu turno, também merece realce o art. 227, do Código Civil português, de 1967, que assenta que "Quem negocia com outrem para conclusão de um contrato, deve, tanto nos preliminares quanto na formação dele, proceder segundo as regras da boa-fé, sob pena de responder pelos danos que culposamente causar à outra parte"

8. Os sistemas jurídicos são elaborados, observando normas de Direito Consuetudinário, pautadas, principalmente no Direito Natural, em que duas colunas existem: a da boa-fé, sempre triunfante, que deve estar sempre de pé, e a da má-fé, que deve permanecer em ruínas.

9. Todo o Direito dos povos obedece esse princípio de acolher a boafé e de repelir a má-fé.

3 Princípio da liberdade contratual.

10. É preciso distinguir entre liberdade de contratar e liberdade contratual.

11. Se é verdade que todos devem ser livres para contratar, realizar o contrato em si, o mesmo não ocorre com a liberdade contratual, considerada como a possibilidade de livre disposição de seus interesses pelas partes. Estas devem, sem restrições, regular esses interesses, clausulando-os, sem colisão de direitos. O direito de um contratante vai até onde se inicia o direito do outro.

12. Na liberdade contratual os interesses humanos existem, teoricamente, em pé de igualdade, pois o mais forte, economicamente, no mais das vezes, reduz, na avença, a área de atuação do direito do mais fraco, que fica desprotegido, juridicamente, no momento em que o contrato surge, bem como nas revisões dessa contratação.

13. Realizado o pacto, sob essa pressão, a lesão ocorre, sendo difícil e custosa a reparação, para repor certos valores destruídos.

14. Se dermos força demais à liberdade contratual, ficando o homem livre, na sociedade, sem condições de discutir razoavelmente sobre suas convenções, 
será ele o mesmo que um pássaro libertado de uma gaiola, ao fácil alcance de um gavião, pronto para atacá-lo. Pouco duraria a liberdade daquele.

15. A liberdade deve ser escrava do homem e não para escravizá-lo.

Como bem lembrou o romanista italiano, professor Pierangelo Catalano, da Universidade de Roma, "La Sapienza" (in Correio Brasiliense, Direito e Justiça, Brasilia-Brasil, de 21 de setembro de 1990, p. 5), a propósito da dívida externa dos Países em desenvolvimento, na conferência inaugural do VII Seminário Roma-Brasília, estamos a assistir o nascimento de uma "nova escravidão por dividas"

16. Por essa razão, não há que se falar em liberdade, em Direito, sem que existam limitações na ordem jurídica. E essas limitações encontram fundamento nos princípios gerais de direito e no próprio Direito Natural.

4 Princípio da função social do contrato.

17. Por esse princípio os contratos desempenham um relevante papel na sociedade, nacional e internacionalmente, considerada.

18. Pelos contratos, os homens devem compreender-se e se respeitar, para que encontrem um meio de entendimento e de negociação sadia de seus interesses e não um meio de opressão.

19. Para que esse espírito de fraternidade nos contratos se preserve, no âmbito de direito interno, têm os Estados modernos lançado mão de normas cogentes, interferindo nas contratações, com sua vontade soberana, para evitar lesões.

20. De futuro, certamente, no plano internacional, deverá existir um sistema jurídico de ordem pública, para que se coíbam abusos nas contratações, preservando-se, assim, principalmente, a própria dignidade dos povos em desenvolvimento.

21. Até que isso ocorra, com um Tribunal Internacional, com força executória de suas decisões, é preciso que os órgãos internacionais, atualmente existentes, reclamem e recomendem, com sua força moral, o cumprimento dos princípios gerais de direito, nas contratações, principalmente no tocante à dívida externa dos países em desenvolvimento. 
5 - Princípio da comutatividade dos contratos e da eqüidade.

22. Desde a "mancipatio", inserida na Lei das XII Tábuas, de 450 a.C., em que, por ato "per aes et libram", as obrigações das partes contratantes eram pesadas, nos pratos de uma balança, em praça pública, devendo ser cumpridas as formalidades legais, ficando esses pratos em eqüidistância, atestando a igualdade das mesmas obrigações assumidas, representa-se esse contrato como verdadeiro símbolo da Justiça (a balança), até hoje preservado pelos povos.

23. Essa igualdade e equilíbrio, nas relações jurídicas são tãoimportantes, que, já entre os romanos, Celso (Ulp. 1 inst., D. 1, 1, 1 pr.) conceituou o Direito como "a arte do bem e da eqüidade" ("ius est ars boni et aequi").

24. Assim, a comutatividade, nos contratos, é princípio essencial de Direito, porque exige a equivalência das prestações e o equilíbrio delas, no curso das contratações, pois, por ele, as partes devem saber, desde o início negocial, quais serão seus ganhos e suas perdas, importando esse fato a aludida equipolência das mencionadas prestações.

6 Princípio da cláusula "rebus sic stantibus"

25. A cláusula "rebus sic stantibus" surgiu na Idade Média, da frase seguinte: "Os contratos que têm trato sucessivo e dependência futura devem ser entendidos estando as coisas assim", ou seja, como se encontram no momento da contratação ("contractus qui habent tractum sucessivum et dependentiam de futuro, rebus sic stantibus intelliguntur").

26. Ela se apresenta com roupagem moderna, sob o nome de teoria da imprevisão, tendo sido construída pela Doutrina, com o intuito de abrandar a aplicação do princípio "pacta sunt servanda" ("os pactos devem ser cumpridos"), quando da alteração brusca das situações existentes no momento da contratação.

27. Todavia, essa cláusula, considerada, pela Doutrina e pela Jurisprudência brasileiras, como existente em todos os contratos, ainda que não expressamente contratada, apresenta-se com três pressupostos fundamentais, autorizadores de sua aplicação.

28. Deve ocorrer, primeiramente, uma alteração radical do contrato, em razão de circunstâncias imprevistas e imprevisíveis (álea extraordinária). Todavia, há situações que ocorrem, de um momento a outro e que podem ser 
previstas e causam desequilíbrio contratual, ficando obstada de aplicar-se a teoria da imprevisão (cláusula "rebus sic stantibus").

Quanto a esse primeiro pressuposto, por exemplo, o Supremo Tribunal Federal e o Superior Tribunal de Justiça brasileiros têm considerado inaplicável a teoria da imprevisão, desconsiderando a cláusula "rebus sic stantibus" em face da inflação, porque, embora cause esta o desequilíbrio do contrato, ela é previsível.

29. Por outro lado, é preciso que exista enriquecimento, prejuízo, inesperado e injusto por um dos contratantes.

30. O terceiro pressuposto é a onerosidade excessiva, que sofre um dos contratantes, tornando-se, para ele, insuportável a execução contratual.

31. Como visto, torna-se impossível a aplicação da cláusula "rebus sic stantibus", ante a não-ocorrência de um desses três pressupostos.

7 Princípio da onerosidade excessiva e a lesão objetiva.

32. No meu entender, é melhor utilizar o princípio da onerosidade excessiva, fora do âmbito mais amplo da teoria da imprevisão, porque ele mede, objetivamente, o desequilíbrio no contrato, com a insuportabilidade de seu cumprimento por um dos contratantes.

Com essa lesão objetiva, um dos contratantes só tem benefícios e o outro só vantagens, o que configura, em linhas gerais, a "laesio enormis" do Direito Romano, quebrando-se o princípio fundamental dos contratos, o da comutatividade.

33. Realmente, na época do Baixo Império, com a Constituição de Diocleciano e Maximiliano, teria surgido a idéia de que um contrato poderia resolver-se, quando trouxesse desvantagens para um dos contratantes. Acontecia no caso de venda de imóvel, quando o vendedor fosse forçado a vendê-lo, em condições desvantajosas, por preço inferior à metade do seu valor real.

34. Com Justiniano (C. 4, 44, 2 e 8) aperfeiçoou-se, em verdade, o instituto da lesão.

Somente na Idade Média, por influência do Direito Canônico, desenvolveu-se a noção de justo preço. Se alguém vende muito abaixo do valor da coisa está em estado de necessidade, precisando do preço para viver.

35. O Código Penal brasileiro (art. $180, \S 1^{\circ}$ ) repulsa esse pensamento de desigualdade entre o valor do objeto vendido e o preço, quando pune como crime 
de receptação culposa a aquisição ou recebimento de coisa com "desproporção entre o valor e o preço", assentando, em tal situação, que "deve presumir-se" que o objeto vendido tenha sido "obtido, por meio criminoso". A lei penal brasileira, como visto, não tolera essa desproporção, o preço vil, em apoio do princípio da comutatividade contratual.

36. Também, e por analogia, a Lei n. 1.521, de 26.12.1951 (art. $4^{\circ}$, alínea $b$ ), ao tipificar o delito de usura real, reclama a presença de dois elementos, a saber: o subjetivo, a mostrar o abuso por inexperiência ou leviandade do outro, e o objetivo, que existe com a desigualdade dos objetos das prestações, que não podem exceder um quinto ou vinte por cento de seu justo valor, pois, além desse limite máximo, é obstado o "lucro patrimonial"

37. Bem aponta o professor brasileiro Cáio Mário da Silva Pereira (Lesão dos Contratos, Ed. Forense, Rio de Janeiro, $4^{\mathrm{a}}$ ed., 1993, p. 187) que a lesão apurar-se-á objetivamente, "na desproporção evidente e anormal das prestações, quando um dos contratantes aufere ou tem possibilidade de auferir do contrato um lucro desabuscidamente maior do que a contraprestação a que se obrigou"

E completa esse mesmo professor brasileiro (o.c., p. 213) que, "após quase dois mil anos de existência, o instituto da lesão continua presente, na proteção ao contratualmente mais fraco, e tudo indica que veio para ficar "

38. Por sua vez, o Código brasileiro de Proteção e Defesa do Consumidor (art. 39, inciso V) considera prática abusiva "exigir do consumidor vantagem manifestamente excessiva"

39. Ao Direito repugna a atuação ilícita e mesmo o enriquecimento indevido, pois a lesão está presente neles.

40. O fenômeno da lesão, no direito contratual moderno, deve ser encarado objetivamente. Causado o prejuízo, ocorrendo o desequilíbrio nas prestações, deve ser o reestabelecimento da igualdade entre os contratantes.

Isto porque, o agravamento unilateral da prestação de uma das partes contratantes torna excessivamente onerosa sua obrigação e, via de conseqüência, insuportável o cumprimento desta. 
B Modificação Unilateral da Taxa de Juros.

41. O caráter ilícito da alteração unilateral da taxa de juros da dívida externa é, realmente, preocupante, pois continua a ser admitido, no plano internacional, em verdadeiro desrespeito ao já aludido princípio da comutatividade dos contratos, em quebra da eqüidade e em prejuízo dos Países devedores.

42. Destaque-se que, nos contratos bilaterais, essencialmente, que nascem do livre entendimento das partes, regulando seus próprios interesses, não há que admitir-se situação que permita a manipulação dos valores contratados, ainda que isso conste de cláusula contratual, que, certamente, será abusiva e, mesmo, ilícita.

43. Bem salientou o embaixador da República Argentina e professor da Universidade de Buenos Aires, Miguel Angel Espeche Gil (Ilicitude da Elevação Unilateral das Taxas de Juros da Dívida Externa, in Cuadernos Del Parlatino n. 2, sobre "La Deuda Externa", Editora do Parlamento Latinoamericano, São Paulo Brasil, fevereiro de 1994, pp. 113 e 115), no Seminário Roma-Brasília (agosto de 1990), na Capital brasileira, que "a alegação do caráter ilícito dos aumentos das taxas de juros sustenta-se em que os mesmos, decididos unilateral e ilimitadamente pelos credores, constituem atos de usura" sendo certo que a dívida, ao invés de diminuir, continua aumentando, malgrado a realização dos pagamentos.

44. O Código Civil brasileiro acolhe princípio relevante, em seu art. 1.125, e que pode ser aplicado, por analogia, na hipótese em tratamento, ao declarar nulo o contrato de compra e venda, quando fica ao arbítrio exclusivo de uma das partes a taxação do preço. Esse preceito legal, que veio das Ordenações Filipinas, de $1603\left(4,1, \S 1^{\circ}\right.$ ), descendem do Direito Romano (D.18, 1, fr. $35, \S 1^{\circ} ; 45,1$, fr. 17).

\section{C - Efeitos da Onerosidade Excessiva.}

45. A considerar os efeitos da onerosidade excessiva, no plano do direito interno, entendo, como melhor, que se adote o princípio da revisão contratual, para repor as partes em sua situação anterior à contratação, em igualdade de condições, devendo o juiz declarar resolvido o contrato, caso as partes contratantes ou uma delas não-concorde com o resultado da revisão judicial, proposta e malograda. 
Essa liberdade existe, porque não pode o juiz, pelo mesmo princípio da bilateralidade dos contratos, decidir sobre sua alteração, unilateralmente, a não ser que os contratantes tenham estabelecido cláusula de arbitragem. Neste caso, nada impede que o árbitro seja o juiz de Direito ou um terceiro.

46. No âmbito internacional, não existe, por enquanto, um Tribunal com força coercitiva, quanto a suas decisões, que possa rever esses contratos, de que resulta a dívida externa, dos Países em desenvolvimento; muito menos para declarálos resolvidos.

É preciso, portanto, nesse caso, estabelecer-se um sistema de arbitragem internacional, por um organismo, como o Tribunal de Haia, que pode ser consultado e em que as partes contratantes devem confiar, ante sua posição de neutralidade.

47. No dizer do professor brasileiro, André Franco Montoro (in La Deuda Externa, cit., p. 7), presidente do Instituto Latino-Americano e do Conselho Consultivo do Parlatino, "não se trata de rever ou anular disposições das dividas atuais. Mas, sim, de procurar estabelecer critérios para contratos futuros, a partir do reconhecimento dos erros e resultados calamitosos dos programas de ajuste que vêm sendo praticados"

48. O ideal seria que, para os débitos pendentes, fossem respeitados os resultados das consultas, que os Países devedores pretendem fazer, à Corte Internacional de Justiça de Haia (art. 96 da Carta das Nações Unidas e art. 65 do Estatuto dessa mesma Corte), por solicitação da Assembléia Geral das Nações Unidas, conforme proposta do professor Montoro (o.c., p. 19).

49. Acrescento a essa proposta a de que, nos contratos futuros, os contratantes façam inserir, neles, cláusula de arbitragem, nos moldes do Direito Internacional.

D - Conversão da Dívida Externa em Projetos de Natureza Ambiental.

50. Muito tem sido feito no sentido de que se implantem projetos em defesa da ecologia.

O ser humano degrada a natureza e ela falta à sua própria vida.

51. O meio ambiente é, verdadeiramente, a reserva de sobrevivência da humanidade, o pulmão do mundo, que está sendo destruído, principalmente, pelos 
Países industrializados, que lançam seus detritos sem maiores cuidados e preocupações. Todos esses meios de enriquecimento selvagem, sem perceber conseqüências, em devastação contínua da vida natural, hão de parar um dia.

Esses mesmos Países são responsáveis pela reposição dos bens da natureza por eles destruídos.

52. O homem deve preocupar-se, desde ora, com a defesa do meio ambiente, e em ritmo acelerado, para que não pereça, em breve, a humanidade, que sente o crescimento populacional, a conseqüente falta de alimentos, a pobreza e a ausência, cada vez maior, do oxigênio.

53. Essa defesa ecológica pode ser realizada por várias iniciativas, inclusive pela conversão da dívida externa em projetos de natureza ambiental, como de reflorestamento, de proteção de parques e de áreas naturais, de despoluição das águas e do ar, etc.

54. De ressaltar-se, neste ponto, a contribuição das professoras brasileiras Isabella Soares Micali e Maristela Basso (a conversão da dívida externa latino-americana em projetos ambientais: uma resposta da "novíssima ordem econômica internacional" ao problema do endividamento e do meio ambiente, in Revista da Faculdade de Direito da Universidade Federal do Rio Grande do Sul, Ed. Livraria do Advogado, Porto Alegre, Brasil, novembro/1993, v. 9, n. 1, p. 176), que concluem que "a conversão da divida externa em projetos ambientais é, portanto, um elemento revelador desta novíssima ordem econômica internacional, que se baseia numa responsabilidade comum e numa parceria econômica e humana da qual todos tiraremos proveito"

55. No Brasil, a defesa do meio ambiente faz-se pela Lei n. 6.938, de 31.08.82, regulamentada pelo Decreto n. 88.351 , de 01.06 .83 , que por seu art. $14, \S$ $1^{\circ}$ declara que o poluidor, "independentemente da existência de culpa" é obrigado " a indenizar ou reparar os danos causados ao meio ambiente e a terceiros, afetados por sua atividade. O Ministério Público da União e dos Estados terá legitimidade para propor ação de responsabilidade civil e criminal por danos causados ao meio ambiente"

Como visto, esse texto de lei assegura, em casos de dano ecológico, a existência de responsabilidade civil objetiva, pura, ou seja, independentemente da ocorrência de culpa do poluidor, seja por ato lícito seu ou por fato jurídico, em que não há participação de vontade. 
E a Constituição da República Federativa do Brasil, de 05.10.88, por seu art. 225, assenta que "todos têm direito ao meio ambiente ecologicamente equilibrado, bem como de uso comum do povo e essencial à sadia qualidade de vida, impondo-se ao Poder Público e à coletividade o dever de defendê-lo e preservá-lo para as presentes e futuras gerações"

56. O Brasil, dentre outros Países Latinoamericanos, tem procurado estudar a implantação de projetos ambientais, para a conversão de sua dívida externa, como fizeram a Costa Rica, a Bolívia e o Equador.

E - Resumo da nossa proposta.

57. Pelo estudo realizado, passamos a resumir o teor da nossa proposta, que se desenvolveu neste trabalho:

a. Aplicação, pura e simplesmente, da teoria da onerosidade excessiva, causadora de lesão, independentemente da teoria da imprevisão ou da cláusula "rebus sic stantibus" O simples desequilíbrio contratual, objetivamente considerado, causa a necessidade de revisão contratual, com a conseqüente reposição ao "statu quo"

b. Impossibilidade de alteração unilateral, pelos credores, das taxas de juros, sob pena de atuação abusiva e mesmo ilícita, causando a nulidade dessa modificação realizada sem o mútuo consenso dos contratantes.

c. Necessidade de respeitar-se, quanto aos débitos dos contratos existentes, o parecer da Corte Internacional de Justiça de Haia, a que deve ser submetida a questão sobre a dívida externa dos Países em desenvolvimento.

d. No tocante aos contratos futuros, necessidade de inserir, neles, cláusulas de arbitragem, escolhendo, de preferência o árbitro e seus eventuais substitutos, em ordem cronológica, na cláusula contratual. Esse árbitro deve ser, de preferência, a Corte Internacional ou outro Órgão equivalente.

e. Incentivo aos Países em desenvolvimento à implantação de projetos de conversão da dívida externa de natureza ecológica.

58. Em verdade, como questionou o romanista italiano professor Sandro Schipani (Palabras de Saludo, in "La Deuda Externa de los Paises Latinoamericanos, Perfiles Juridicos, Economicos y Sociales", Ed. Ceisal, Sassari, Itália, Ensayos II, 1991, p. 1), Diretor do Centro de Estudos Latinoamericanos da II 
Universidade de Roma "Tor Vergata": "se se aplicarem os princípios gerais do direito, estaria já paga a dívida externa da América Latina?"

59. Deve, assim, existir uma compreensão geral dos credores dos Países em desenvolvimento para que a humanidade cresça e se espiritualize, na idéia da construção de um mundo novo, fraternal e amigo, em que a matéria seja secundária nos projetos de aprimoramento da cultura dos povos, da justiça social e do bem comum.

São Paulo, dezembro de 1997. 